CEPAL REVIEW 87 • DECEMBER 2005

\title{
Policies for economic diversification
}

\author{
Dani Rodrik
}

$\mathrm{T}$

his article begins by showing that not all developing countries concentrate their exports in products which make intensive use of natural resources or cheap labour, and that those which also export some products typical of more developed countries tend to grow faster, apparently independently of their human capital endowment or the quality of their institutions. For this purpose, an index is used which measures the degree to which each country displays this type of export mix. This is an idiosyncratic phenomenon which seems to be linked with the capacity to undertake the production and export of new products. There is therefore a place for incentive policies, accompanied by the ability of the government to recognize failed attempts and to stop subsidizing them. Because of the idiosyncratic nature of the phenomenon, it is not possible to propose universal solutions, but the author does set out ten principles to be borne in mind in policy design in each country.

Dani Rodrik,

Rafiq Hariri Professor of International Political Economy,

John F. Kennedy School of Government, University of Harvard.

$\infty$ dani.rodrik@harvard.edu 
I

\section{Introduction}

Great ideas never die, and in many ways some of the key ideas spearheaded by Raúl Prebisch -one of the greatest Latin American economists who ever livedare very much back in vogue. Prebisch thought that the economic structure really makes a difference: that what countries produce -whether they specialize in primary industries or in manufacturing- makes a real difference to their economic performance. This idea, which in some respects is a very plausible one, disappeared from the consciousness of most North American trained economists in the last couple of decades, but I think it is fair to say that now it is coming back. Indeed, the main theme of this presentation will be to elaborate on that idea -that what you produce matters- and try to draw some policy implications from that proposition.

This idea is at variance with much of the economic philosophy that guided policy makers in the 1980s and 1990s, not only in Latin America and the Caribbean but all over the world. The basic idea that motivated the economic reforms made in those decades was that policy makers only had to concern themselves with the broad framework: that is to say, that once you established macroeconomic stability and provided the basic parameters of a functioning market economy, with an appropriate regulatory structure, then essentially you could leave the market economy to take care of itself and assign resources efficiently in both a static and a dynamic sense, on the assumption that the economy would generate economic growth on its own and that such growth would be automatic once macroeconomic stability was in place and the market fundamentals were in operation.

We are now learning, however, that while many of the reforms undertaken in the 1990s -especially those in the macroeconomic, fiscal and monetary fields-were absolutely necessary, in certain respects some of the other reforms may not have been particularly well targeted on the factors that really generate economic growth. In this respect, it is important to have a better understanding of how the productive structure contributes to the growth process, what that structure is, and what that implies for policy design in both the micro and macro spheres.

\section{II}

\section{The productive structure and the quality of the export basket}

I am now going to argue that the productive structure matters for economic growth; that the kinds of goods produced are important, and that the economic fundamentals and comparative advantages in and of themselves do not really determine the productive structure: there is a certain element of arbitrariness, a certain idiosyncratic nature, in what a country actually ends up producing, and the role of public strategies, in

$\square$ This article is based on the Fifth Raúl Prebisch Memorial Lecture, delivered by the author at the Economic Commission for Latin America and the Caribbean (Santiago, Chile, 31 August 2005). the best of all possible worlds, is not to predetermine what a country can or can not produce, but to ensure that it ends up producing those types of goods which are most growth-generating. In fact, when we look closely at the details of how successful industries are actually generated -how they "get off the ground"-we find that in almost all such cases public intervention has played a significant role.

The basic argument in support of the above, at the most general level, is that growth strategies are needed to complement the pursuit of macroeconomic stability with a more productive economic strategy that focuses on the needs of the real sector and does not just assume 
that, once the macro framework is in place, the real sector will take care of itself and will generate the dynamism needed for sustained growth. That leads us to the question of what such a policy framework consists of: a really difficult question because, on the one hand, there has been relatively little serious research, especially by economists, on what we think an appropriate industrial policy framework for low and middle income countries might be, but also because as soon as we start thinking about such policy frameworks we immediately become aware once again of the importance of the specific context and the need that such frameworks must function well. In order for this to be so they must obey some general principles: they need to be highly specific, they must take advantage of the institutional endowment that the country already possesses - which differs from setting to setting- and they must respond to the specific constraints or obstacles that the individual countries face, which likewise differ from setting to setting. Consequently, there is not really a whole lot that one can say about the nature of these policies that is very concrete or operational; all that one can do is to set forth as fully as possible the general design principles for their formulation that need to be taken into account in constructing the policy framework, so that policy makers will at least have some guidelines for this task.

I will now refer to two aspects of these general principles, one being the need to balance the "carrots" and the "sticks", the discipline and the rewards, when designing industrial promotion strategies, and the second being the need for the public authorities, and specifically the public agencies entrusted with productive restructuring, to strike a balance between insulation and embeddedness. On the one hand, they need to be sufficiently insulated from private interests, so that they cannot be captured by them and be "in their pockets", but on the other hand they need to be sufficiently embedded within those private interests, so that they can obtain enough information about where action is needed and what form it should take.

Let me start with an example which I think is quite striking, taken from an article by Imbs and Wacziarg (2003). ${ }^{1}$ Those authors looked at what happens with regard to the concentration of production during the process of economic development, as shown in figures 1 and 2. The vertical axis of both figures is a Gini index

\footnotetext{
${ }^{1}$ See J. Imbs and R.Wacziarg (2003), Stages of diversification,
} American Economic Review, vol. 93, No. 1, Nashville, Tennessee. that relates to either the concentration of employment (figure 1) or that of production (figure 2), across different sectors of the economy. Thus, in an economy in which production is highly concentrated in a single sector, the Gini coefficient is extremely high, whereas in a very diversified economy the Gini coefficient for production or employment would be very low. The

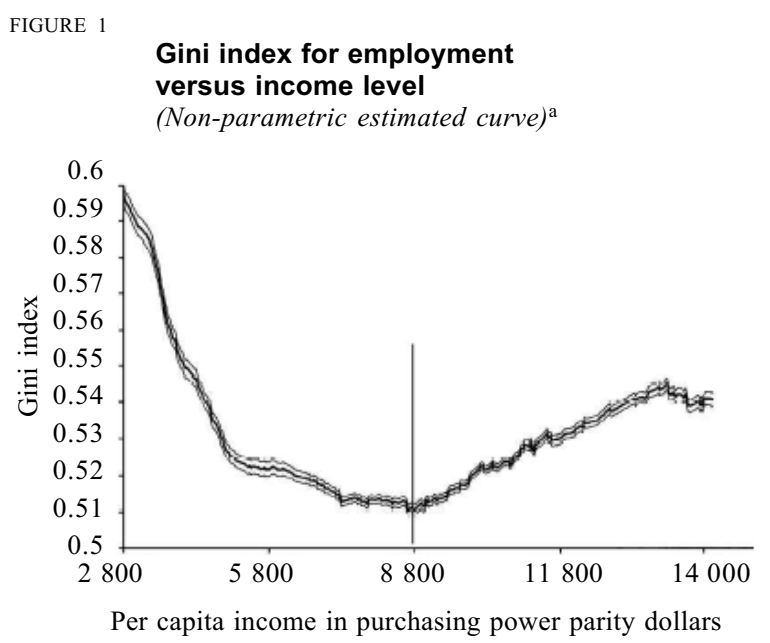

Source: J. Imbs and R. Wacziarg (2003), Stages of diversification, American Economic Review, Nashville, Tennessee, American Economic Association, March.

a United Nations Industrial Development Organization (UNIDO) 3-digit employment data.

FIGURE 2

\section{Gini index for value added versus income level} (Non-parametric estimated curve) $^{\mathrm{a}}$

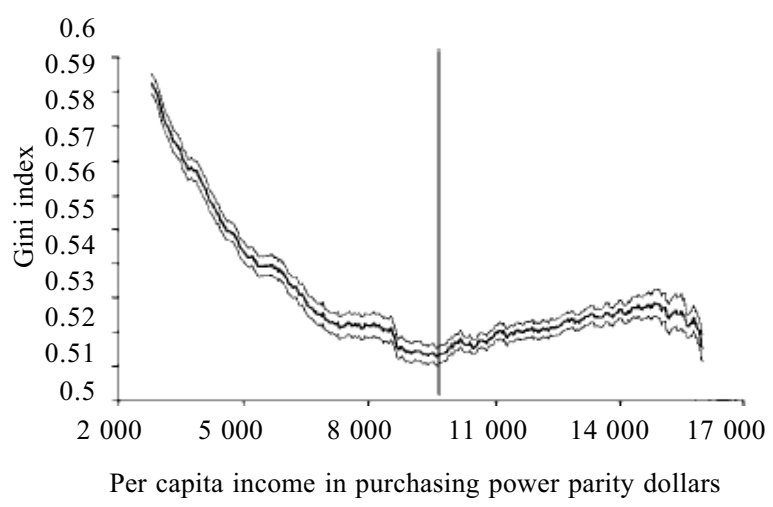

Source: J. Imbs and R. Wacziarg (2003), Stages of diversification, American Economic Review, Nashville, Tennessee, American Economic Association, March.

a United Nations Industrial Development Organization (UNIDO) 3 -digit value added data. 
horizontal axis of both figures shows different levels of income which roughly reflect the evolution of concentration in the course of development. These two economists analyze growth across countries as well as within them over time, so the comments made below are a valid description of a dynamic and do not merely reflect a cross country regularity.

Imbs and Wacziarg found that as countries go from very low levels of income to higher levels, their production pattern becomes much more diversified, and that at sufficiently high levels of income the corresponding curve starts to turn around, which means that a process of concentration begins to take hold. If we look at the turning-point, that is to say, the level of income at which economies start to become more concentrated again, we see that this point is very high, and has not yet been reached in any country of the region. We should therefore concentrate our attention on what happens in the declining part of this curve, which indicates that as countries are becoming less poor, their production structure becomes more and more diversified, or at least if they start from being very concentrated they become less concentrated as they become richer.

From one perspective, this should not come as a surprise at all, but from another perspective, in the case of those who studied for a doctorate in economics in a North American university at any time in the last three or four decades and internalized the policy implications of what they were taught there, leaving aside everything else they might have heard, it could reasonably be assumed -without wishing to deprecate the value of that kind of education in any way- that they were told that in order for a country to get rich and free itself from poverty, it must specialize according to its comparative advantages, and that the difference between countries that were doing well and those that were doing poorly was that the former had decided to exploit their comparative advantages, that is to say, to allocate their resources where they could be best used for realizing that principle, whereas the latter set of countries had done the reverse: i.e., they had not followed the dictates of comparative advantage. Figures 1 and 2 , however, show that to a first and second degree of approximation that story cannot be right as a general description of what drives development, because if it had been right, the countries that would be breaking out of the ranks of poverty would be those that were becoming more concentrated in their production structure: that is to say, the countries which were specializing, rather than those which were becoming more diversified.
The key point in this respect is that, whatever the role that trade and comparative advantage may have played in the development of those countries, the dynamic that drives growth is not fundamentally linked to any notion of static comparative advantage; on the contrary, it is a dynamic which somehow leads some countries to gradually diversify their investments into a whole range of new activities. Thus, the most prosperous countries are those where new investments are being made in new areas, while the countries that have failed are those where this has not taken place.

My own recent research -much of it jointly with Ricardo Hausmann, at the Kennedy School of Government at Harvard- takes a particular approach to this issue in order to quantify some of these relationships and to look for their implications. What we have done is to develop an indicator that measures the quality of the countries' export basket. In order to do this, we first calculated for each product traded (at a fairly disaggregated 6-digit level, so that we are really talking about thousands and thousands of different commodities) the average income level PRODY $(\mathrm{j})^{2}$ of the countries which have exhibited a revealed comparative advantage in that commodity. In other words, we associate with each commodity a particular income level and we take that level as the representative income level corresponding to a country which has a strong comparative advantage in that commodity. Thus, for example, jute is a very low-income commodity, while aircraft are a very high-income commodity, because the countries that have strong comparative advantages in jute tend to be lower-income countries and aircraft are a high-income commodity because the countries that export aircraft have high incomes.

Having calculated this commodity-based indicator, we aggregated across different countries by simply taking their weighted average PRODY(j), using as a weighting factor the share of each product in their export basket. We call this indicator EXPY: a quantitative indicator which is our measure of the quality of the export basket of a country, since it measures the income level associated with that basket. This is one way of quantifying what a country actually produces and the mix of products that that country has developed mastery in producing. It does this by aggregating different goods on the basis of the income levels associated with the factors giving rise to the respective comparative advantages.

\footnotetext{
$2 \operatorname{PRODY}(\mathrm{j})=$ average income level of countries with a comparative advantage for the production of a good $j$ (6-digit Harmonized System).
} 
It is not surprising, then, that (as shown in figure 3) a scatter plot of this EXPY measure against the income levels of different countries reveals a high correlation. This correlation is very high almost by definition, confirming that the rich countries are those that export typical rich countries' goods. What interests me most, however, is not the overall correlation, but the deviations from the regression line: why is it that some countries are significantly above the regression line and some countries are below it, and can this have actual implications for economic performance?

There are about a hundred or so countries in this scatter plot, but we will focus on India and China, because they diverge from the mean. It is very interesting that two countries which have been doing extremely well in recent decades have much higher levels of EXPY than would be expected on the basis of their income level and are thus much further above the regression line than other countries.

China, which is particularly far above that line, is currently exporting a set of commodities -most of them based on electronics, consumer electronics and so forth- which are associated with the income levels of countries with much higher incomes than China; in fact, the income level associated with that country's export basket is six times higher than China's aggregate income level.

Let us now look at the same situation from a somewhat different angle: over time. Figure 4 shows, for a number of Asian and Latin American countries, how this index which measures the quality of export baskets has changed over time and how these different countries rank against each other. There are four Latin American countries in the figure: Argentina, Brazil, Chile and Mexico. It is interesting to note that the first three of those countries, (Argentina, Brazil and Chile) have the lowest EXPY levels in this comparison, i.e., the lowest income content of exports, whereas China's level is close to that of the Asian group and Mexico, and its gap with the latter country has closed significantly over time. This is surprising, because China is still much poorer, compared to these Latin American countries, yet it is exporting a set of goods that are much more sophisticated than those exported

FIGURE 3
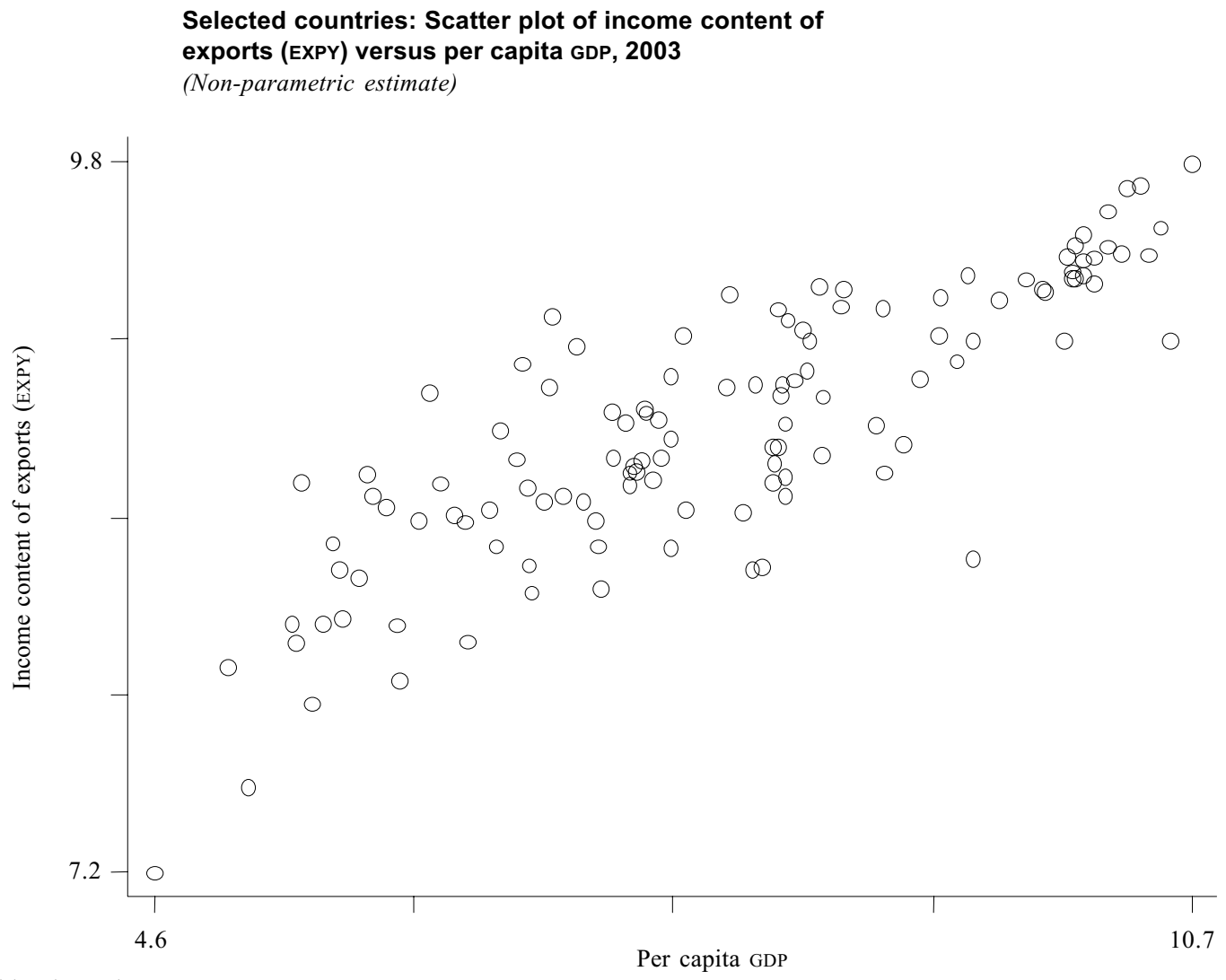

Source: Prepared by the author. 
FIGURE 4

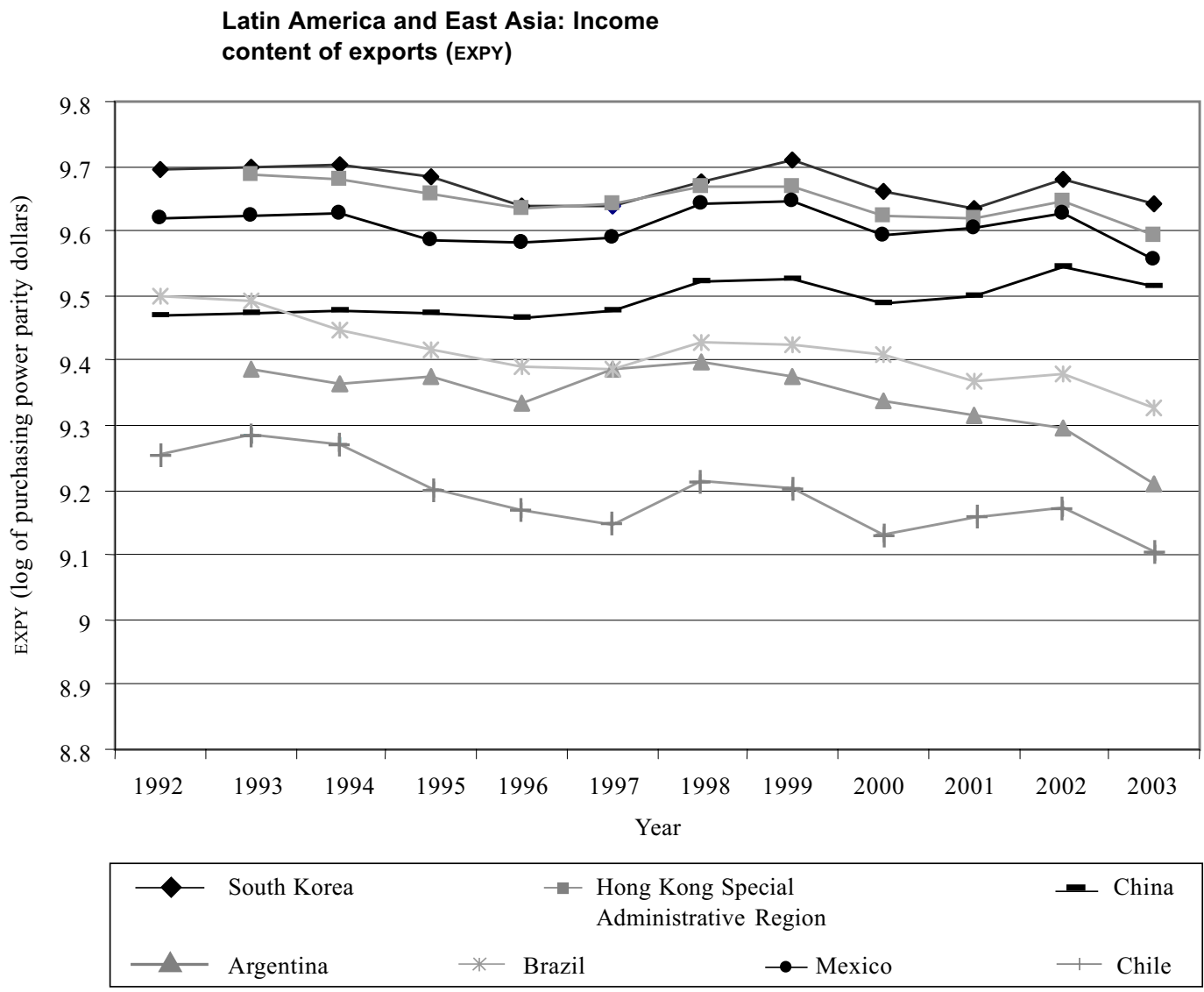

Source: Prepared by the author.

by them. This is partly because of the relatively greater natural resource endowments of the Latin American countries, but I think this is only part of the picture.

If you were to show this to your average neoclassical economist steeped in the tradition of comparative advantage, he or she would say that all that this shows is that countries like China, or South Korea, or Taiwan, or Singapore, which have developed highly sophisticated export baskets, have simply wasted resources by allocating them in areas where they do not have one of the authentic comparative advantages -that of possessing skills which have already been developed- so that in reality these export baskets have been purchased at too high a cost. Therefore, it is important to look at the implications of whether this really matters: whether this particular cross-section of export structure and production structure shows up in the figures as an important predictor of something that we care about. The answer to this question is very much "yes".
Our concentration on this particular measure of export baskets is justified because it turns out that this measure is a quantitatively significant and robust predictor of subsequent economic growth, since countries that latch on somehow to these higher-quality export baskets subsequently register much higher levels of growth than countries that do not. The partial scatter plot in figure 5 shows the growth rate of per capita GDP over a ten-year period, compared with the initial value (in 1992) of the EXPY indicator for different countries, controlling for other factors that are normally included in a growth regression. Essentially, what it shows (after controlling for the initial levels of income and human capital in different countries) is that countries which have managed to generate export baskets that are associated with higher income levels have converged much more rapidly. In other words, if you latch on to these higher-productivity goods, these productivity levels spread to the rest of the economy. That is the dynamic that really drives the process of economic 
FIGURE 5 Selected countries: Per capita GDP growth, 1992-2003 (As a function of 1992 level of EXPY ${ }^{\mathrm{a}}$ )

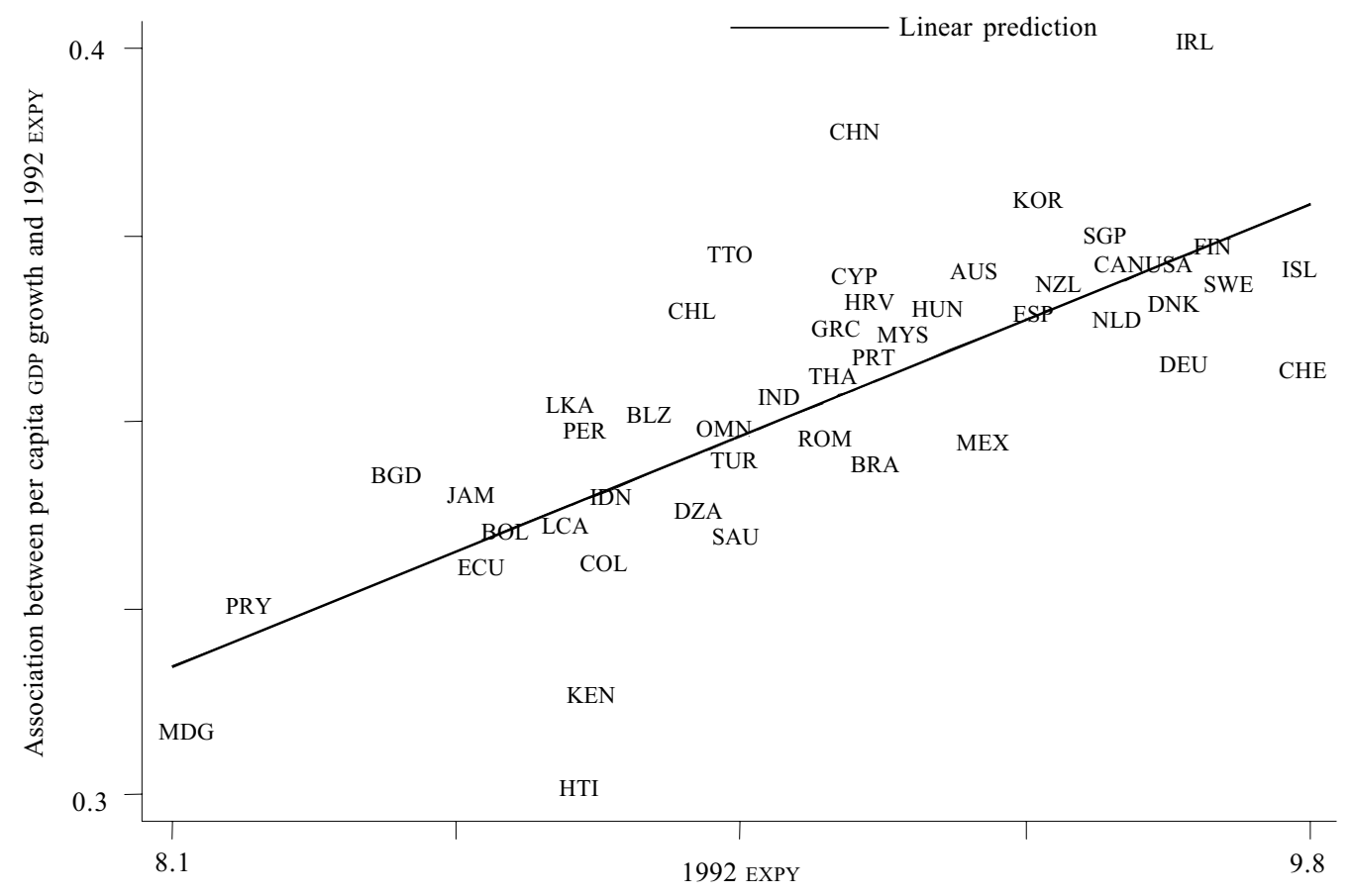

Source: Prepared by the author.

${ }^{a}$ Controlling for initial income and human capital.

growth; this is what explains why a country like China, by producing goods like mobile telephones, refrigerators and television sets, is able to generate much higher productivity gains and spread them to the rest of the economy than it would have been able to do if China had simply produced garments, shoes and toys. This explains the significant normative interest of this particular measure of what a country produces and exports.

Furthermore, when it is sought to explain why certain countries have much higher-quality export baskets than others, most of the factors that are usually considered do not have a lot of explanatory power. As figures 6 and 7 show, neither human capital endowment nor some measure of overall institutional quality help very much to explain why different countries have different levels of EXPY, after controlling for per capita GDP. As we already showed, there is a relationship between EXPY and per capita GDP, but that basically summarizes practically everything that we know, since we do not get much greater explanatory power by including other measures of factor endowment or institutional quality.

It is not possible to explain why China and India have so much more sophisticated export baskets, either on the basis of their relatively high endowments of human capital, or some factor such as a better institutional environment, which may have promoted specialization in the production of more sophisticated goods through some indirect comparative advantage channel. Thus, there are many idiosyncratic elements and, I would argue, a good deal of room for suitable policies to make a difference in the creation of the basket of goods produced, which can help the country in question to grow. What a country produces and exports - the products it becomes good at exportingdepends on a lot more than the economic fundamentals. 
FIGURE 6

Selected countries: Association between EXPY and human capital

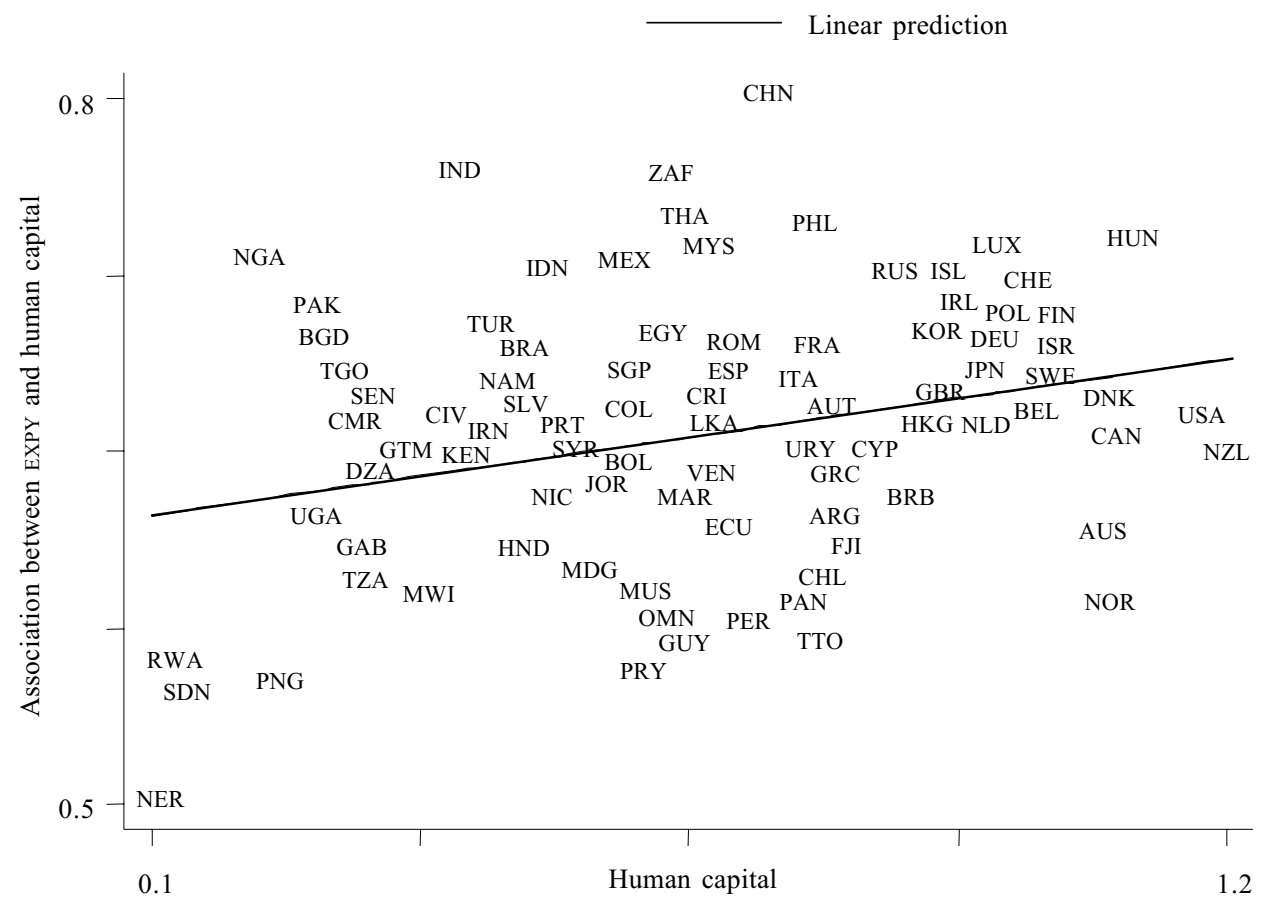

Source: Prepared by the author.

FIGURE 7

Selected countries: Association between EXPY and institutional quality

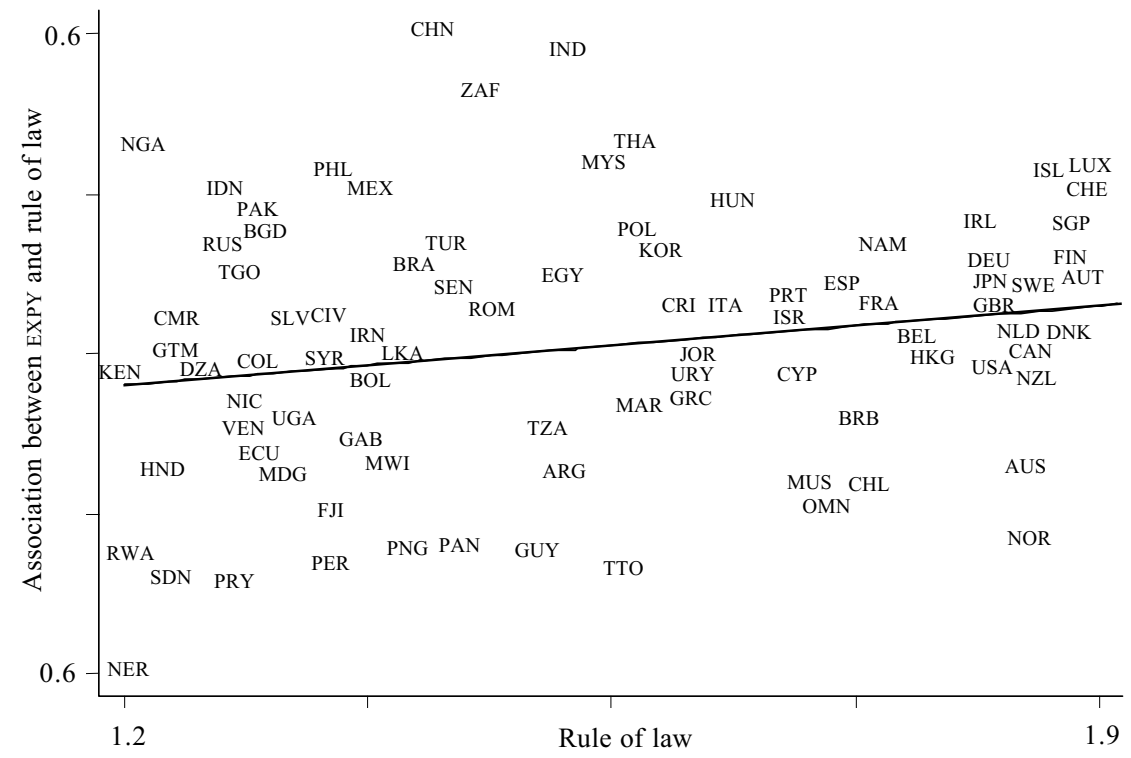

Source: Prepared by the author. 
III

\section{Patterns of specialization and}

\section{the cost discovery process}

The idiosyncratic and (within certain limits) somewhat arbitrary nature of the pattern of specialization can be analyzed from a number of different standpoints. If we analyze at the detailed level what the different countries are specializing in, we see the arbitrariness of this pattern. Bangladesh and Pakistan, for example, are two countries that look virtually identical in terms of their overall endowments of factors that support comparative advantages. One would not expect these two countries to exhibit different patterns of specialization, and at a broad level that is obviously true: neither country is exporting aircraft or semiconductors. On the other hand, when we look in greater detail at the areas in which they are actually specializing, we see big differences: Pakistan specializes in the production of soccer balls, which it manufactures in large numbers, while Bangladesh does none of this, but on the other hand some of the things that Bangladesh exports are hardly found at all in Pakistan. And if one runs up or down the income chain comparing what pairs of countries export, one finds lots of puzzling situations: for example, comparing South Korea and Taiwan, why is it that South Korea is one of the world's biggest -if not the biggest-producers of microwave ovens, while Taiwan virtually does not export such ovens, and likewise, Taiwan supplies most of the world market for bicycles, except for some of the most sophisticated models, while South Korea exports virtually no bicycles.

These are the kind of idiosyncratic elements underlying the fact that some countries develop a mastery that cannot simply be explained through comparative advantages or economic fundamentals: in these cases, one needs to understand how these things happen, particularly when, as I have been arguing, they affect subsequent development. The theoretical explanation for this indeterminacy, which leaves room for these idiosyncratic patterns of specialization or arbitrary forms of specialization to occur, is the idea that, for certain economically well-grounded reasons, freely functioning markets generally fail to supply sufficient investments in new, non-traditional activities. There are many reasons for this, but the two that I would like to emphasize in particular are coordination externalities and information externalities.
Coordination externalities refer to the idea that, in order for any new activity to be profitable, it needs to be accompanied at the same time by substantial investments elsewhere in the horizontal or vertical production chain. Thus, if you are thinking of investing in pineapples in a country which has not previously had significant skills in pineapple production and export, you may also need to make sure that a pineapple packaging plant is going to be constructed. On the other hand, if you are thinking of investing in a pineapple packaging plant, you will want to make sure that a reliable supply of domestic pineapples will be grown, because without these two investments being undertaken simultaneously, neither one of them can be profitable; without some coordination of investments across these different activities you may well end up without a pineapple industry, whereas this could very well have been developed if such coordination had taken place.

There are many different types of information externalities, but the one that I am most concerned with here is the externality that attaches to what I call the "cost discovery process". One of the most important things that entrepreneurs do in a developing country is to discover the underlying cost structure of the economy: that is, how much will it actually cost to produce, say, pineapples in the local economy, once the necessary modifications in off-the-shelf technology have been made, and can they be produced profitably or not. Entrepreneurship is of course always full of uncertainties like this, but in low- and middle-income countries there is an important externality associated with the process that operates along the following lines: if you are the first entrepreneur to invest in pineapples and discover their production cost, and if it finally turns out that you have made a mistake and that you are not in an economy where you can produce pineapples profitably, your losses are entirely private, and you must bear them all yourself, but if instead you have discovered that you can in fact produce pineapples in that country very cheaply and profitably, there is then likely to be a process of entry and diffusion and imitation by other entrepreneurs: this means that you cannot retain or appropriate the full benefits of that 
discovery, so the gains end up being socialized, whereas the losses are private. This is the fundamental asymmetry of any cost discovery process, and this is why cost discovery is generally under-financed in economies with a low level of diversification, so that investments in new non-traditional activities are generally under-financed too.

This means that in these kinds of settings there is a lot of indeterminacy, depending on idiosyncratic factors of luck, the quality of entrepreneurship, what the government does, what it does not do, who you are neighbours with and who you are not, which foreign investor enters the country and which does not, and so forth. Sometimes efforts are made to fill in some of the gaps in this wide range of products which could potentially be produced but apparently are not, but in other cases big holes are left where this is not being done. The question is what public policy can do in these kinds of settings: can it play a successful role in making sure that when such investments in new activities are under-financed, the level of investment can be systematically raised through government action?

\section{IV}

\section{The contribution of industrial policies}

Policy can and often does play such a role. Let us look at a couple of examples of how policy does this in practice. Real exchange rate policy can play a very important role in this respect. The real exchange rate is the most potent form of industrial policy imaginable, because an undervalued real exchange rate is an acrossthe-board subsidy for industries producing internationally tradable goods: an area of activity where exchange rate-related problems are particularly severe and the benefits of discovering new tradable activities are all that much greater because you have the whole world to supply before returns and profits begin to diminish. The scatter plot in figure 8 shows the relationship between a measure of real exchange rate overvaluation during the 1994-2003 period and the quality of the export basket, as indicated by the level of EXPY at the end of the period, controlling for its initial level. The question here is: regardless of the export baskets inherited in 1994, did the levels of the real exchange rate registered after that date make any difference to the quality of those export basket some ten or twelve years later, and the answer is that they did. Once again, India and China are outstanding cases in this figure. In general, countries that are near the origin in figure 8 are countries that had relatively undervalued real exchange rates, while the countries that are far away from the origin are countries that had relatively overvalued exchange rates over this period, and indeed one of the things that stands out in China's performance is that it has been underpinned by a very competitive real exchange rate.

In the context of the theory that I have just briefly described, a competitive real exchange rate, by increasing the relative profitability of real tradable activities (all other factors being equal), increases the number of investments in tradable sectors that become profitable and therefore probabilistically increases the number of profitable industries that get off the ground and eventually become successful. There therefore really is a relationship between the level of the real exchange rate and the quality of exports, although one might expect quite the opposite: that a highly depreciated real exchange rate is a way of lowering labour costs, thus making the country in question more competitive at the lower end of the product spectrum and leading to specialization in labour-intensive products. It turns out in practice, however, that a highly depreciated exchange rate tends to cause countries to rise in the product spectrum in the long run rather than pushing them down. I cannot emphasize this point about the exchange rate too strongly, because this is an area where we have a highly valid alternative role for the exchange rate, contrasting with the consensus that prevailed in Latin America until recently with only a few exceptions (the main one, of course, being the policies pursued by Argentina in this respect).

The argument behind this consensus was that basically the exchange rate should not be a policy variable and that Central Banks and governments should not set either a nominal or a real exchange rate target, since that rate was an equilibrium variable that should be left in complete freedom, except for perhaps just smoothing out short-term fluctuations. From the standpoint of productive diversification, this strikes me as an unsatisfactory stand because it flies in the face of the evidence that we have, which is that competitive 
FIGURE 8

\section{Selected countries: Association between overvaluation of the real exchange rate during 1994-2003 and level of EXPY in $2003^{\circ}$}

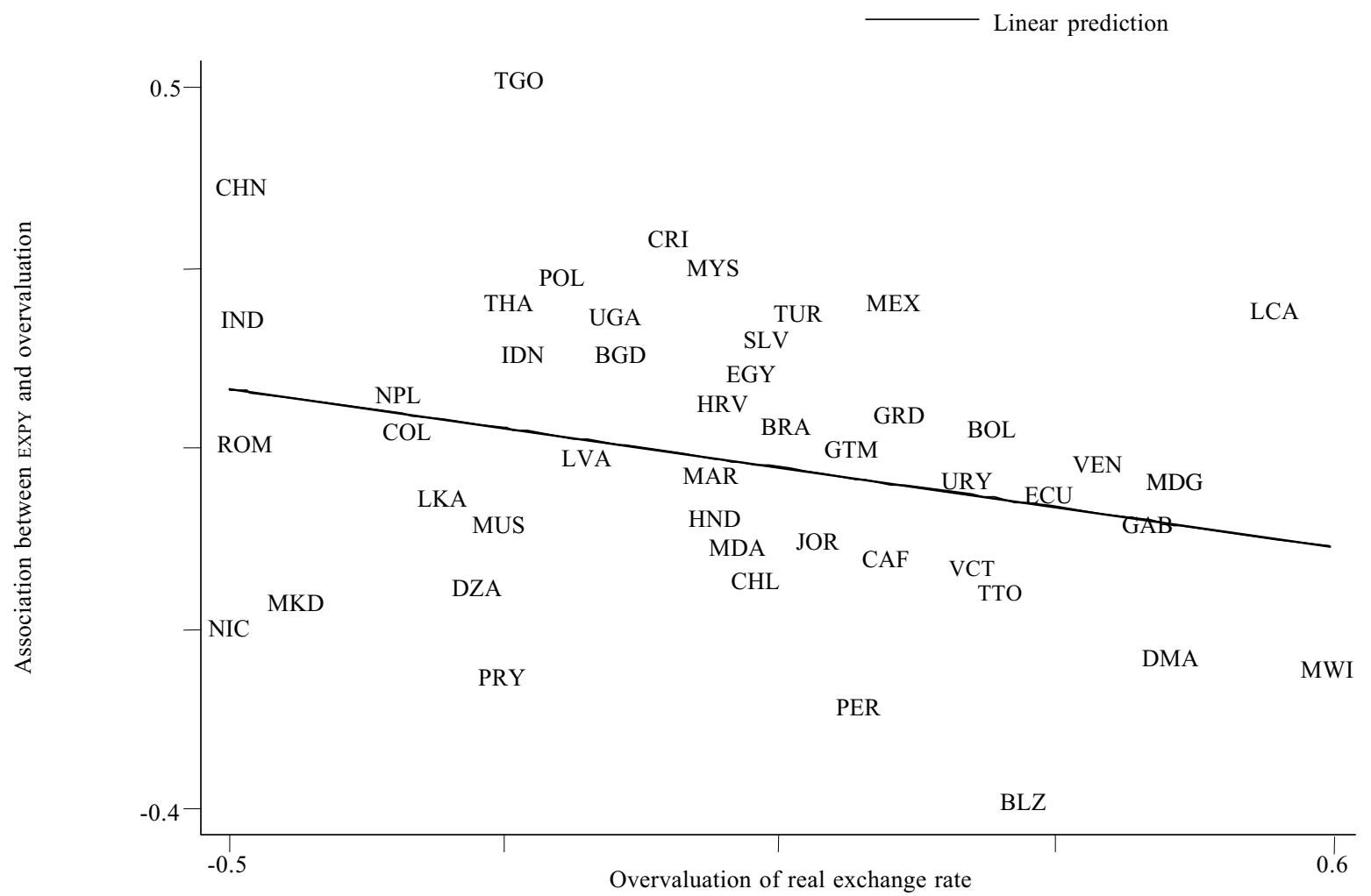

Source: Prepared by the author.

${ }^{a}$ Controlling for initial level of income and human capital.

real exchange rates have been a necessary if not sufficient condition for sustained economic growth in developing countries and that by leaving out the exchange rate as a policy variable, removing it from the range of policies open to governments, we are thereby obliging them to apply industrial policy in a more makeshift way, since if the real exchange rate does not assist the tradable sectors, then this increases the pressure to adopt makeshift policies of the type that I will be considering below.

Policy also matters because when we look at the non-traditional export industries which have been most successful in Latin America (leaving out natural resource-based industries and traditional export industries like garments), we find time after time that some of the most successful cases have been due to the application of various types of industrial policy, State intervention, public-private cooperation, and preferential policies on the part of some other countries.
In Chile, which is a country that is often held up, by those who do not know it well, as a sort of a freemarket miracle, some of the key non-traditional, noncopper exports were the result of intelligent public strategies of very varied kinds, ranging from salmon, which benefitted from the research and development and technological assistance efforts of Fundación Chile, to forestry, which was promoted by a few subsidies in the Pinochet era: for all the market-based fundamentalism of that regime, there was one area where explicit industrial policies were applied, and that was the forestry sector.

In the case of Mexico, we should not forget the role of the preferential tariff policies applied under the North American Free Trade Agreement (NAFTA). These are simply industrial policies under a different guise, because they are really just another way of making the playing field uneven: compared with export subsidies, for example, they have the advantage that somebody 
else ends up paying the price rather than the exporting country, but in many respects they work in a similar way. Thus, none of the cases listed in Box 1 are the result of markets just working on their own, "level playing fields" and the like.

A final example of how policy matters is provided by China. That country has relied extensively on direct investment, but of course it has done so in a very strategic way, and transnational corporations wishing to enter and operate in China have been required to team up with domestic firms, as shown in table 1. It is now recognized that part of the success of foreign direct investments in China is due precisely to the fact that they have been a collaborative exercise between domestic (mostly State-owned) and foreign firms. This view of corporate ownership structure is interesting because the industries are not dominated by foreign firms but are joint ventures, and an important point to note in this respect is that these firms, by being able to transfer technology and enjoying the benefits of State protection, were able to generate capabilities in the hands of domestic investors, which would not have occurred otherwise. In this sense, China is very different from a typical Latin American country: in Latin America, there would not be this pattern of a preponderance of joint ventures, and instead whollyowned foreign firms would be much more prevalent.

It can therefore be said that Chinese preferences, strategies and policies undoubtedly made a difference as to the kind of industries that the country would specialize in, and some of these firms eventually became extremely successful: the IBM/Great Wall joint venture shown in table 1 recently bought IBM's personal computer business, and is now one of the world's largest PC manufacturers. I hope I have put forward a reasonably interesting and convincing argument about two things so far: i) that what a country produces matters, and that the production structure should therefore be a major policy concern, and ii) that there are many ways in which policies can influence the production structure, and they can therefore play an important role in determining the pattern of specialization.

Box 1

LATIN AMERICAN NON-TRADITIONAL EXPORT SUCCESS STORIES

Brazil: steel, aircraft, and (to an important extent) shoe production are all due to import substitution industrialization, receive subsidized credit, and in the case of aircraft production, are State-owned.

Chile: salmon production was due to the efforts of Fundación Chile; the grape industry was the result of public research and development activities in the 1960s, and forestry received subsidies in the past.

Mexico: motor vehicle production was initially due to import substitution industrialization policies and later benefited from preferential tariff policies under the North American Free Trade Agreement (NAFTA).

Top five export items to the United States in $2000^{\mathrm{a}}$

\begin{tabular}{llc}
\hline Country & Item & Value (millions of dollars) \\
\hline Brazil & Aircraft & 1435 \\
& Footwear & 1069 \\
& Non-crude petroleum & 689 \\
& Steel & 485 \\
Chile & Chemical wood pulp & 465 \\
& Copper & 457 \\
& Grapes & 396 \\
& Fish & 377 \\
Mexico & Lumber & 144 \\
& Wood & 142 \\
& Motor vehicles & 15771 \\
& Crude oil & 11977 \\
& Computers and peripherals & 6411 \\
& Ignition wiring sets & 5576 \\
\hline
\end{tabular}

${ }^{a}$ Using the 4-digit Harmonized System. 
TABLE 1

China: Major consumer electronics firms, by ownership type

\begin{tabular}{|c|c|c|c|}
\hline Market segment & Foreign-owned & Joint venture & Non-FDI ${ }^{\mathrm{a}}$ \\
\hline Mobile phones & - Motorola & $\begin{array}{l}\text { - Motorola/Eastcom } \\
\text { - Nokia/Capitel, Southern } \\
\text { - Siemens/Mil subsidiaries } \\
\text { - Samsung/Kejian } \\
\text { - SAGEM/Bird }\end{array}$ & $-\mathrm{TLC}$ \\
\hline Personal computers & $\begin{array}{l}- \text { HP } \\
- \text { Dell }\end{array}$ & $\begin{array}{l}\text { - IBM/Great Wall } \\
\text { - Toshiba/Toshiba Computer } \\
\text { (Shanghai) } \\
\text { - Epson/Start } \\
\text { - Taiwan GVC/TCL }\end{array}$ & $\begin{array}{l}\text { - Lenovo (previously Legend) } \\
\text { - Founder } \\
\text { - Tongfang }\end{array}$ \\
\hline "Brown" goods & & $\begin{array}{l}\text { - Sony/sVA } \\
\text { - Philips/Suzhou CTV } \\
\text { - Toshiba/Dalian Daxian } \\
\text { - Great Wall Electronics/TCL }\end{array}$ & $\begin{array}{l}\text { - Changhong } \\
\text { - Konka } \\
\text { - Hisense } \\
\text { - Skyworth } \\
\text { - Haier } \\
\text { - Panda } \\
\text { - Xoceco }\end{array}$ \\
\hline "White" goods & - Siemens & $\begin{array}{l}\text { - Samsung/Suzhou } \\
\text { Xiangxuehai } \\
\text { - Electrolux/Changsha } \\
\text { Zhongyi } \\
\text { - LG/Chunlan } \\
\text { - Mitsubishi/Haier } \\
\text { - Sanyo/Kelon, Rongshida } \\
\text { - Sigma/Meiling } \\
\text { - Hong Leong (SG)/Xinfei } \\
\text { - Toshiba Carrier/Midea }\end{array}$ & $\begin{array}{l}\text { - Changling } \\
\text { - Gree }\end{array}$ \\
\hline
\end{tabular}

Source: Prepared by the author.

${ }^{\mathrm{a}}$ FDI $=$ Foreign Direct Investment.

\section{Policy formulation}

The foregoing has important implications for policy formulation, and here again we encounter the difficulty of how little we know in this respect. Any kind of appropriate policy in this area will have to be devised within the country in question by people who know its institutional endowments well, for there is no such thing as a manual of industrial policy, or a set of do's and don'ts to be applied across the board. What we can do is to try to formulate a set of general principles that we think all good policy frameworks should obey, leaving the details of the design to the individual countries and their policy makers. This area is no different from any of the other areas that we have been concerned with, so if the objectives pursued are fiscal sustainability and inflation control, their importance will warrant their being incorporated as general principles of good policy, but the manner in which they are to be achieved will obviously depend to a large extent on what is feasible in each case; the actual instruments and the operational agenda required by those objectives will have to be designed in detail at home. 
The same can be said with regard to the provision of an appropriate institutional environment for the protection of property rights. Recognition of the importance of property rights may be a desideratum of economic policy, but when it comes to determining how to protect those desired rights in practice, this cannot be done in general, all-embracing terms. Some countries, such as China or Vietnam, may find it easier and more effective to provide effective property rights for investors through highly heterodox arrangements, while others may find that it is easier just to import Western codes and legislation and blueprints off the shelf. This is really a general issue, and industrial policy and productive policies in general are no exception as regards the impossibility of establishing a very specific concrete agenda. So what can we say as regards general guidelines?

I should like to emphasize a couple of points in this respect. One is that these arrangements need to have both discipline and rewards built into them: you need to have both a carrot and a stick. You need a carrot because, as I have already argued, when entrepreneurs find that there are no extra profits or rents to be obtained from engaging in cost discovery, they will be reluctant to invest in it, and that is not what we want. There will therefore need to be carrots: rewards for entrepreneurs who make this kind of new investment, even though we know the risks of bottling up resources in activities that may potentially end up being unproductive and may also create potential for rent-seeking. So in general terms these arrangements need to combine the carrot and the stick, that is to say, they should encourage investments in non-traditional areas, while weeding out the investments that fail. Taking this standpoint, we may evaluate the industrial policy frameworks of different kinds of countries. East Asia, for example, is famous for having combined both the carrot and the stick: investors in South Korea, Taiwan and Singapore were showered with different kinds of incentives -export subsidies, tax incentives, credit subsidies and so forthbut there were also very clear performance standards, often but not always based on export performance, and when these standards were not fulfilled, these governments were quick to punish the firms or withdraw their incentives, so it is now generally recognized that a large part of the success of East Asian industrial policies was due to the fact that they combined the carrot and the stick: they did not only offer incentives.

The import substituting industrialization (III) phase in Latin America, in contrast, was a case of mostly carrot and no -or very few- sticks, because under ISI firms were basically protected with higher levels of import barriers and were subsidized through negative interest rates and so forth, but there was very little in the system to ensure that the firms that ended up not performing as expected and became failures would have their subsidies withdrawn, so that those resources could be released for more productive activities. What happened, I think, under ISI was that, while that system produced a number of world-class industries in Latin America, it also produced a very wide range of inefficient sectors and activities that were allowed to keep on operating for far too long because it provided incentives but no punishment for unsatisfactory performance.

In the 1990s in Latin America, there was a 180 degree turnaround in the incentives structure: firms and entrepreneurs now faced all the discipline in the world, because they had to operate in markets with no protection, open to international competition, and there were no incentives because it was impossible to seek help from governments, since they were no longer able to provide it. In that decade, Latin American firms were in an environment with as much stick and as much discipline as one could imagine, but too little carrot: hardly any incentives.

What I think has happened in these circumstances is that the firms which have done well have done very, very well indeed, as reflected in the high productivity rates of those industries that have survived, but clearly there has not been enough investment in new activities, so that those extraordinarily high productivity levels had not spread to the rest of the economy: a huge gap has developed between the aggregate productivity level of the economy and the level of the firms which have been successful. In Latin America, there was no process like that observed in Asia, as registered in the "gang of four" countries in the 1960s, 1970s and 1980s and, more recently, in China, where basically the whole economy has moved forward, and not just some parts of the firms or sectors.

The second general principle I should like to mention is the need to combine a bureaucratic structure with a certain amount of embeddedness. Traditionally, economists think of regulation as a top down process, in which there is a bureaucratic regulatory agency which, whenever there is uncertainty in the system, issues a set of rules, expects the private sector to live according to those rules, but then keeps that sector at arms length. Thus, there is only an arms length relationship between the regulatory body or the bureaucrats and the private sector they regulate. I think this is a mistaken view of 
how productivity policies should be formulated: mistaken because, whatever the agency that is entrusted with formulating such policies, it needs information, and this information exists first and foremost in the private sector. It is the private sector, the firms and investors who know where the obstacles are: whether they lie in the market, in market externalities or, as often happens, in problems caused by government regulations and red tape. It is not the bureaucracy but the private sector that knows where the problems are and how they should be solved, and there therefore needs to be a mechanism whereby the public sector, the agencies and the bureaucracy in general can obtain this information from the private sector. If this is not done - if there is a simple top down, arms length regulatory model, the policies imposed may be ineffective or even harmful. The right model, I think, lies in between these two extremes, and its objective should be to create a form of strategic collaboration and coordination between the public and the private sectors, with the aim of identifying the most serious obstacles to productive restructuring. So, just as economic development and productive change are processes of self-discovery, the kind of arrangement I have in mind is a process of discovery as well, both of the opportunities that exist for creative, collaborative action and of the most suitable types of instruments for achieving this objective.

\section{VI}

\section{Some final reflections}

With regard to the general design principles for industrial policies that I have briefly discussed above, there are some general conclusions that I would like to highlight.

One of these is that, when thinking about industrial policies, what is important is to concentrate on the process of their generation, rather than on their outcome. There is a tendency to become obsessed with the instruments that are to be used: are they going to be tax credits?, credit subsidies?, export subsidies?, export processing zones?, and so on. This is equivalent to overlooking the question of what the policy formulation process is or ought to be: a process of discovering precisely what problems are to be solved, in the first place, before focusing on exactly what type of instruments are to be used to solve them. Getting the institutional setting and the process right are the key considerations in this respect, and I think in general that applying a first-best policy in the wrong institutional setting is likely to do more harm than using a second-best policy in the right setting, for in the latter case, at least you are going after the right target, even if your instrument is a second-best one.

Another conclusion is that one should not be overly concerned about identifying the sectors in which to act. Once again, the process is what matters: these sectors should not be selected on the basis of some preconceived idea of what they are, but should ideally emerge naturally from this kind of collaborative process, and I think eliciting information on the private sector's willingness to invest in the different areas, subject to removal of the obstacles in question, is an essential part of the process of considering sectoral priorities. Finally, an important implication emerging from all this is that the key to applying successful industrial policies is not the ability to "pick winners" but the ability to discard losers. The usual argument against industrial policy is that governments are incapable of picking winners, and that is absolutely right, but I think that it is the wrong way of looking at what it is that we are trying to do. If the process of productive change outlined above is correct, then it is a process of experimentation, where there is a lot of uncertainty about which investments will work and which will fail. This uncertainty prevails not only in the public sector, but also in the private sector, so it is inevitable that, even with optimal policy configurations, some of the investments promoted will end up being failures. Indeed, if none of them end up in this way, this would be a sure sign that not enough is being done, because the logic is that if you have a portfolio of projects, some of them are going to be successes, but some will be failures. If it turns out that all the projects which received investments are successful, this means that not enough has been invested, since the return has been much higher than could reasonably be expected.

So it is not a case of not making any mistakes at all. The distinction between policy regimes that are 
going to work and those that will not, is that some policy regimes are self-correcting and incorporate a mechanism for recognizing mistakes and gradually withdrawing support from them. That is, by and large, what happened in the most successful cases of industrial policies in Asia and, in a lot of cases, it is also what has been happening in China. So the key institutional capacity, the key institutional design feature that needs to be incorporated in any such policies is a true automatic sunset clause which operates by making the incentives or promotion regimes temporary, by building in periodic reviews, by ensuring that there is accountability, by ensuring that the reviews are transparent and open for all to see, and, in short, by providing mechanisms whereby, when ventures are failing, there are automatic processes that cause support to be withdrawn. Using this kind of approach is obviously much less demanding than assuming omniscience, as happens when it is assumed that industrial policies should not be formulated unless one can pick winners, for only if one were omniscient could it be assumed that one would never make a mistake and would always pick winners. The incorporation of an automatic sunset clause in industrial policy considerably reduces such unrealistic demands: it just requires the capacity to recognize a mistake.

For reasons already explained earlier, it is impossible (and undesirable) to specify ex ante the policy results that the type of architecture discussed above will yield. Everything depends on the opportunities and constraints that will be identified through the collaborative process. Nonetheless, it is possible to list (see box 2) some general "design principles" that can help in the formulation of industrial policies.
A consensus currently seems to be emerging regarding the broad lines of what an appropriate growth strategy for developing countries should be like. In this emergent consensus, a key role is assigned to macroeconomic stability, and while I have not said much about this, except in relation to exchange rate policy, I would certainly agree that macroeconomic stability is a necessary although often not sufficient condition for growth.

Another key element in this emergent consensus, besides macroeconomic stability, is the importance of high-quality institutions, especially in the case of the regulatory framework. While this is perfectly true, I think there is currently too much emphasis on institutions as an economic development strategy: in a sense, the market fundamentalism of a few years back is now being replaced by institution-based fundamentalism. While I am absolutely convinced that high-quality institutions are a sine qua non for longterm economic development, their effects are not so evident when most of the action is in the short term: it takes a long time to build institutions, and there is evidence that you can get a lot of growth with the institutions that you have, if you are creative and imaginative. Although the evidence we have is that you do not need a very ambitious programme of institutional reform in order to get growth going, however, you will nevertheless eventually need high-quality institutions in order to catch up with more advanced countries. If China continues to grow at its present rate, it will have to make an inordinate number of institutional reforms, even though it must be admitted that so far it has achieved outstanding growth with very little institutional reform. I would suggest that, instead of a very ambitious agenda of institutional reform at the

Box 2

TEN DESIGN PRINCIPLES FOR ECONOMIC DIVERSIFICATION POLICIES

1. Provide incentives and subsidies only for "new" activities.

2. Establish clear benchmarks and criteria for success and failure of subsidized projects.

3. Build in automatic sunset clause for subsidies.

4. Target economic activities (technology transfer or adoption, training, and so on), not industrial sectors.

5. Subsidize only activities that have clear potential to provide spillovers and demonstration effects.

6. Vest the authority for carrying out industrial policies in agencies with demonstrated competence.

7. Make sure agencies are monitored closely by a "principal" who has a clear stake in the outcomes and has political authority at the highest level.

8. Make sure implementing agencies maintain channels of communication with the private sector.

9. Understand that even under "optimal" industrial policies "picking losers" will sometimes occur.

10. Endow promotion activities with the capacity to renew themselves, so that the cycle of discovery can become an ongoing one. 
outset, which eats up political capital, it would be better to spend that capital on an explicit growth strategy in the short term, focused on promoting restructuring and investment in new industrial activities. This is useful and perhaps even necessary during the early stages, when it is important to get the economy going, to endow the private sector with dynamism, and this calls for an explicitly production-oriented strategy.

In conclusion, I would say that, rather than necessarily having a specific policy of the kind that I have been talking about, what is really important is to have a production-oriented mentality. There is an enormous difference between a government that has such a mentality and one that basically believes that macroeconomic stability and the market fundamentals are enough to get an economy going: between a government that actually listens to businessmen, when they come and complain about something, and one that assumes that any businessman who comes and asks for something is a crook. There is a difference between a government that views the exchange rate as something that can really make a difference for productive development, as opposed to one that sees the exchange rate as a mere equilibrium variable best determined in the financial market, and finally there is a world of difference between a government that is actively thinking about how it can foster productive collaboration with the private sector in order to identify or at least help to identify new investments and areas of investment and ways in which it can organize itself to provide the best kind of support, and a government that basically considers that productive restructuring is a process that will take care of itself and that it is not the government's job to get involved in it. 